\title{
Improved understanding of the pathophysiology of sepsis: Setting the scene for potential novel adjunctive therapies
}

\author{
J M Chausse, MB ChB; L Malekele, MB ChB; F Paruk, PhD (Clinical Medicine), Cert Crit Care (SA), FCOG (SA), MB ChB \\ Department of Critical Care, Steve Biko Academic Hospital and Faculty of Health Sciences, University of Pretoria
}

Corresponding author: F Paruk (Fathima.Paruk@up.ac.za)

\begin{abstract}
The occurrence of sepsis in the critically ill population is a dreaded phenomenon when taking into consideration the devastating complications associated with the disease. Despite its high incidence and unacceptably high mortality, this complex syndrome remains poorly understood in terms of defining the disease, detecting the presence or absence of an infection, and therapeutic strategies to optimise immediate and long-term outcomes. Global efforts to address these issues coupled with significant advances in medical technologies and our improved understanding of the pathophysiology of the disease have led to some exciting developments in the domain of adjunctive therapies for sepsis. In particular, interest has focused around immunomodulation strategies and metabolic resuscitation. Some of these therapies sound particularly promising in terms of the early available evidence. The concept of personalised or individualised medicine takes centre stage when considering such therapies, as it is becoming increasingly evident that in order to achieve benefits, we need to introduce appropriate therapies at the right time, the right dose and for an appropriate duration. This review encapsulates a selection of these new adjunctive therapies.
\end{abstract}

S Afr J Crit Care 2018;34(1):4-8. DOI:10.7196/SAJCC.201.v34i1.361

The global landscape of sepsis reveals its incidence to be rising and that the associated mortality remains unacceptably high in the critically ill population. ${ }^{[1-3]}$ This is despite significant advances in our understanding of the pathophysiology of the disease as well as improvements in technology, microbiology, molecular biology and therapeutic strategies, which have significantly enhanced our overall medical care. Worldwide, sepsis is perceived as a major burden and universal efforts are being directed towards its prevention, further elucidating its pathophysiology, refining its definition, improving our ability to diagnose the disease and seeking therapeutic strategies that would further reduce the current mortality rates and improve post survival quality of life. ${ }^{[4]} \mathrm{A}$ dramatic improvement in our understanding of the pathophysiology of the disease in the last two decades, together with our increasing appreciation of the importance of individualised or personalised therapy in the critically ill patient, has been key in considering a number of novel therapeutic strategies in patients presenting with sepsis or septic shock. These treatment modalities are purported to modulate or interrupt the host's physiological response to sepsis. The present review explores the rationale and the current evidence for a selection of such therapies.

\section{Pathophysiology of sepsis}

Sepsis is defined as the occurrence of a life-threatening organ dysfunction due to a dysregulated host response to an infection. ${ }^{[5]}$ Septic shock necessitates the additional presence of hyperlactaemia $(>2 \mathrm{mmol} / \mathrm{L})$ and the need for vasopressors to maintain a mean arterial pressure (MAP) of $65 \mathrm{mmHg}$ despite adequate volume resuscitation.

The pathophysiology of sepsis involves an intricate interplay of immune dysfunction, as well as endothelial dysfunction, alterations in the gut microbiome and an activated coagulation system. In the last few decades, the incidence of sepsis attributed to Gram-negative bacteria has overtaken that of Gram positive bacteria, and Gram-negative organisms now comprise the most common causative pathogens of septic shock among adults in the intensive care unit. Components of lipoteichoic acid (Grampositive bacteria), lipopolysaccharide (Gram-negative bacteria), fungal antigen or viral particles are recognised by the innate immune system as pathogen associated molecular patterns (PAMPs) by the human host's pathogen recognition receptors (PRRs) which include the tolllike receptors. ${ }^{[6-8]}$ The PAMP-PRR complex triggers a cascade of events characterised by a local chemokine response at the site of sepsis as well as a systemic hyperinflammatory reaction which is largely driven by cytokine release and characterised by endothelial dysfunction, hypercoagulation and uncontrolled fibrinolysis. The severity and magnitude of each of these responses is largely dependent on the virulence of the pathogen as well as host factors, which include comorbidities, site of infection, time to initiation of source control, physiological reserve, nutritional status, age and possibly genetic predisposition to sepsis.

The cytokine response of the innate system is initially proinflammatory (interleukin-1 (IL-1), tumour necrosis factor (TNF) $\alpha$, IL-6, IL-8, interferon- $\gamma$, migration inhibitory factor (MIF)) and then followed on by an anti-inflammatory comeback (IL-10, IL-4, IL-13, transforming growth factor- $\beta$ ). Pro-inflammatory cytokines induce a cytokine storm and this is instrumental in provoking endothelial cell dysregulation, thereby increasing its permeability, which results in extravasation of large molecules and fluid into the interstitium. ${ }^{[9,10]}$ Nitric oxide released from the endothelium has a vasodilatory effect on the macro-circulation, which further perpetuates hypotension, hypoperfusion and reduced oxygen delivery. ${ }^{[11]}$ Cytokines also stimulate the endothelial cells to acquire a prothrombotic tendency, which results in the formation of microthrombi. This leads to hypoperfusion in the microcirculation which drives cellular hypoxia as well as mitochondrial dysfunction culminating in multiorgan dysfunction syndrome (MODS) and ultimately death if left unabated. ${ }^{[12,13]}$ Cytokine-mediated attachment 
of neutrophils to the endothelium also contributes to occlusions within the microcirculation further, perpetuating hypoperfusion and compromised cellular oxygen delivery, further exacerbating endothelial and organ dysfunction. ${ }^{[14]}$ As such, an excessive pro-inflammatory cytokine storm is associated with the development of MODS and a high mortality. ${ }^{[15]}$ The anti-inflammatory response attempts to attenuate this process by reducing the actual number as well as diminishing the functional ability of the circulatory lymphocytes and monocytes. Thus, the host is predisposed to immunoparesis, and the increase in mortality in this scenario is largely attributed to the occurrence of secondary nosocomial infections. ${ }^{[16]}$ To ascertain precisely which phase of the cytokine response is predominating (pro-inflammatory or anti-inflammatory) is not easy, as cytokines exhibit extensive variability and also have very short half-lives. ${ }^{[17]}$ In extreme situations, the patient's history and clinical scenario may shed light as to which phase is predominant - if the host exhibits a florid MODS or alternatively features of extreme immunosuppression.

While neutrophils play a pivotal role in controlling local inflammation and bacterial clearance, the reactive oxygen species (ROS) produced by them are also believed to drive endothelial and mitochondrial dysfunction typical of sepsis. ${ }^{[18]}$ Additional immune alterations include monocyte and macrophage dysfunction. Immunosuppression follows shortly after the onset of inflammation and is postulated to be mediated by PD-1 (programmed cell death-1), which is expressed on activated T cells, natural killer cells as well as B cells. It is the exhaustion of T cells which results in immunosuppression. ${ }^{[19,20]}$ In terms of the adaptive immune response, there is a relative lymphocytopenia and an increase in the proportion of T helper type 2 cells, which also predisposes to immunosuppression. ${ }^{[21]}$

Thrombin formation, apart from being driven by cytokine stimulated endothelial disruption, also occurs due to the depletion of natural anticoagulants (protein C, protein S, antithrombin and thrombomodulin), which further exacerbates the hypercoagulable state. The severity of the hypercoagulable state is predominantly dependent on the magnitude of cytokine production as they drive this process. ${ }^{[22]}$

Mortality in sepsis is largely dependent on the number as well as the duration of organ dysfunctions or the development of immunoparesis which renders the host vulnerable to subsequent infections. Additionally, imbalances in the metabolic, endocrine, coagulation cascade and gut microbiome are also implicated in driving this deadly disease.

In the critically ill patient, there are profound changes that occur in the microbial ecology of the gut (type, volume and virulence of bacteria) and it is suggested that strategies to prevent the proliferation of virulent pathogens may have an impact on outcomes. ${ }^{[23]}$ As such, novel therapeutic strategies are positioning around immunomodulation, restoration of the redox imbalance, metabolic resuscitation and manipulating the gut microbiome, among others.

\section{Role of adjunctive therapies}

The current standard of care includes the rapid administration of appropriate antibiotics and early source control coupled with strategies to ensure haemodynamic stabilisation, organ support and the optimisation of oxygen delivery to prevent cellular hypoxia. Taking into account the multifactorial pathophysiology of the disease, several adjunctive therapies have been suggested in an attempt to interrupt, or at least modulate, certain pathways known to contribute to organ failure.

\section{Immunomodulation}

Immunomodulatory strategies include inhibiting the host's innate immunity, cytokine inactivation, immune-inhibition (during a predominantly pro-inflammatory phase), immune-stimulation (during a predominantly anti-inflammatory phase) and the administration of pharmacological agents for their anti-inflammatory properties. Several trials pertaining to many of these therapies have yielded disappointing results, and the lack of their efficacy is attributed partially to the concept that such therapies would only work if offered when a window of opportunity arises during specific phases of the immune response, and thus, the blanket implementation of these therapies to all patients with sepsis is unlikely to demonstrate a universal survival benefit. ${ }^{[24-27]}$ The partial removal of cytokines by extracorporeal techniques on the other hand appears to offer benefits in appropriately selected patients. ${ }^{[28-30]}$

\section{Extracorporeal removal of cytokines}

The rationale for this therapy is to reduce the magnitude of the cytokine storm and therefore limit the cytokine mediated endothelial dysfunction, hypercoagulation and mitochondrial failure which drives tissue hypoxia and MODS. A number of modalities have been utilised to achieve this. Plasma or whole blood exchange, coupled plasma filtration and high volume haemofiltration have not demonstrated tangible benefits in sepsis. ${ }^{[31-34]}$

The use of haemoadsorption therapies seems attractive and appears to hold promise. This strategy is based on the concept of clearing a proportion of the harmful cytokines and inflammatory mediators by circulating the patient's blood past a highly absorptive membrane or through a sorbent containing cartridge, thereby attenuating the proinflammatory sequelae. Devices may be used as stand-alone (pumpdriven), or incorporated into extracorporeal circuits, such as those used for haemofiltration or ECMO. Devices include among others the Polymyxin B-binding fibre column (PMBFC), which removes cytokines and endotoxins, and CytoSorb (CytoSorbents $\mathrm{GmbH}$, Germany). The use of the PMBFC device in patients with intraabdominal sepsis initially demonstrated a significant reduction in mortality but a subsequent meta-analysis of 6 available trials has not confirmed this finding. ${ }^{[35,36]}$

CytoSorb removes middle-sized molecules by means of a haemoadsorption cartridge made of a suspended column of divinylbenzene beads, which are $300-600 \mu \mathrm{m}$ in diameter (each bead is slightly larger than a grain of salt) and highly porous. ${ }^{[37]}$ The spaces between these beads allow molecules the size of 10000 to 50000 Daltons $(\mathrm{Da})$ - the molecular size of the majority of cytokines - to be adsorbed via hydrophobic interactions. Adsorption occurs in a concentration-dependent manner and, as such, cytokines are never altogether depleted from the patient. Albumin (70000 Da) adsorption is spared. The adsorptive surface area of the cartridge exceeds $40000 \mathrm{~m}^{2}$ and this is probably the reason why the device demonstrates promise unlike the other available blood purification techniques in sepsis. The device may be utilised for up to 24 hours in a patient, and usually patients require 1 to 3 such cycles of therapy to be administered. Utilisation of this device has demonstrated reductions in the amount of vasopressor use, shock reversal and an observed mortality rate that is less than that predicted by conventional outcome prediction tools. ${ }^{[37-39]}$ These data emanate from observational studies and case reports. Typically, patients presenting early (within 24 hours of onset of septic shock) with vasopressor non-responsiveness and organ dysfunction are deemed as potential candidates for this therapy. The device has been used in more than 40000 treatments without any evidence of serious or major adverse events. There are currently numerous prospective trials being conducted and there has also been the establishment of a global registry to clearly define its role, particularly in sepsis and other hyperinflammatory conditions. ${ }^{[40]}$ 


\section{Low-dose glucocorticosteroids}

The rationale for corticosteroid therapy is based on its ability to attenuate inflammation and improve cardiovascular function. ${ }^{[41]}$ The improved cardiovascular function is attributed to an augmentation in the systemic vascular resistance as well as a mineralocorticoid driven improvement in the volume of the intravascular compartment. It is a domain that courts debate and has been shrouded with many uncertainties as the precise dose, mode of administration and duration remain to be clearly elucidated. Two recent large trials evaluated the role of corticosteroids in septic shock and they demonstrated contradictory conclusions pertaining to mortality outcomes. ${ }^{[41,42]}$ The multicentre placebo controlled APROCCHSS (Activated Protein C and Corticosteroids for Human Septic Shock) trial randomised 1241 patients with septic shock to receive corticosteroids (50 $\mathrm{mg}$ hydrocortisone bolus every 6 hours intravenously, $50 \mu \mathrm{g}$ fludrocortisone enterally daily) and/or activated drotrecogin alpha together with their respective placebos. The 90 -day mortality was significantly lower ( $43 \%$ v. $49.1 \%$; $p=0.03$ ) in the corticosteroid group compared with the placebo group. The ADRENAL (ADjunctive coRticosteroid trEatment iN criticAlly ilL Patients With Septic Shock) trial randomised 3568 patients with septic shock to receive $200 \mathrm{mg}$ hydrocortisone daily as a continuous intravenous infusion or a placebo. The 90 -day mortality was similar $(27.8 \% \mathrm{v}$. $28.8 \% ; p=0.5$ ) in both arms of the study. ${ }^{[42]}$ Interestingly, both trials demonstrated that in terms of secondary outcomes, the administration of corticosteroids was associated with earlier resolution of shock (more vasopressor-free days) and earlier cessation of mechanical ventilation compared with placebo. The mortality benefit in the APROCCHSS trial may be attributed to a number of reasons, including the following: corticosteroids were administered early (within 24 hours of onset septic shock); the corticosteroids were administered as bolus therapy (there was no loading dose in the ADRENAL trial and this would affect the time taken to achieve adequate therapeutic levels); and the patients appeared to be more sick (higher severity of illness scores and higher doses of vasopressors in the APROCCHSS trial compared with the ADRENAL trial). The role of fludrocortisone in septic shock remains to be elucidated as the dose prescribed in the APROCCHSS trial was small and further hydrocortisone also exhibits mineralocorticoid effects. Current evidence thus suggests that the administration of low-dose corticosteroids is associated with a higher proportion of shock reversal and a mortality reduction. ${ }^{[41,43]}$ Although its administration is associated with hypernatraemia and hyperglycaemia, current evidence suggests that it may be prudent to consider corticosteroid administration in patients with septic shock who are unable to achieve adequate perfusion pressures despite appropriate fluid therapy and vasopressor administration. In such instances the early use of $50 \mathrm{mg}$ hydrocortisone 6-hourly for between 3 and 7 days, or until the need for vasopressors dissipates, would be regarded as reasonable.

\section{Intravenous immunoglobulins}

The rationale for polyclonal intravenous immunoglobulins is that their administration would neutralise endotoxins and spare the consumption of the host's own antibodies. Analysis of 5 trials with low risk of bias demonstrated no mortality benefit in a recent Cochrane review. ${ }^{[4]}$ Current evidence does not support their routine use in septic shock. ${ }^{[4,45]}$

\section{Metabolic resuscitation}

The mitochondrial dysfunction that accompanies sepsis occurs early and is largely driven by the ensuing cytokine storm, which propagates cellular hypoxia. Initially, the mitochondria are believed to go into hibernation as a protective measure during times of high cellular stress. It is during this so-called 'hypermetabolic state' that the body's main powerhouse conserves energy, only partaking in those functions absolutely vital for the survival of the cell. This mitochondrial dysfunction is instrumental in perpetuating MODS. ${ }^{[46]}$ Untreated or inadequately treated sepsis ultimately culminates with irreversible mitochondrial dysfunction and eventually, if the disease is not abated, MODS and death ensues. Metabolic resuscitation alludes to attempts at recruiting the functions of the hibernating mitochondria.

Recruiting mitochondrial efficiency is also believed to impact positively on the body's redox balance and on its immunity. ${ }^{[12]}$ Strategies suggested include the use of micronutrients and pharmacological agents.

\section{Thiamine}

Thiamine is an essential cofactor for pyruvate to enter the Krebs cycle and ultimately generate ATP. Thiamine deficiency diverts pyruvate to the conversion of lactate. ${ }^{[46]}$ In one study, thiamine deficiency was identified in $35 \%(n=79)$ of patients with septic shock. ${ }^{[47]}$ Thiamine supplementation versus the use of a placebo in this subset of patients has been shown to reduce hyperlactaemia and lead to a survival difference in relation to time to death. While further data are awaited, it would be prudent to consider thiamine supplementation in patients with sepsis who have poor nutritional intake, a history of ethanol abuse, are elderly, have hyperemesis gravidarum re-feeding syndrome, or are receiving renal replacement therapy ${ }^{[46]}$ One should also consider thiamine deficiency in patients who manifest with unexplained lactic acidosis. ${ }^{[48]}$

\section{Vitamin C, vitamin E, selenium and zinc}

Vitamin C administration is purported to confer mitochondrial protection through its antioxidant effect. ${ }^{[46]}$ It is also believed to improve microcirculatory flow, as well as restore endothelial integrity, and similar protection is suggested with vitamin E, zinc and selenium. ${ }^{[49-52]}$ Selenium and zinc contribute to the scavenging of free radicals and should thus reduce oxidative damage to cells and tissues. They should be provided as per the daily recommended allowances.

A recent single-centre retrospective study compared an intravenous regimen of high-dose vitamin C (1.5g q6hr), thiamine (200 mg q12hr) and hydrocortisone (50 $\mathrm{mg} \mathrm{q} 6 \mathrm{hr}$ ) with a control group that did not receive thiamine or vitamin C. ${ }^{[53]}$ There were 47 patients in each group. Vitamin $\mathrm{C}$ and thiamine were administered for 4 days and the hydrocortisone for 7 days, unless the patient was discharged before these timeframes. The cohort that received this regimen exhibited less organ dysfunction and a significantly reduced mortality. While the suggested regimen would be relatively easy to implement, the routine use of this regimen is not recommended taking into account that this was a small retrospective single-centre study, it lacks internal validity, the long-term consequences of high-dose vitamin $\mathrm{C}$ are unknown, it is unclear which component(s) of the regimen was instrumental in achieving an improved mortality benefit, and the findings still need to be externally validated. While the results are promising, they should not change current practice until there is definitive evidence to support the administration of high doses of vitamin C.

\section{Pharmacological agents}

Pharmacological agents such as coenzyme Q10, melatonin, glutamine and $L$-carnitine are currently being explored for their role in metabolic resuscitation. Melatonin in particular has been shown to reduce oxidative stress and improve mitochondrial function in sepsis. ${ }^{[54]}$ Further evidence 
is required prior to making any firm recommendations regarding the use of high-dose micronutrients for metabolic resuscitation.

\section{The microbiome}

The gut is a highly immunologically active component of the human body and is involved in perpetuating the systemic inflammatory response. In critically ill patients, the microbiological milieu changes drastically in the gut, such that the actual number of organisms and their virulence is altered. This is largely attributed to gut hypoperfusion and may be further influenced by the use of proton pump inhibitors, the administration of broad spectrum antibiotics, vasopressors or selective decontamination of the digestive tract. ${ }^{[55,56]}$ During critical illness there is a shift that favours the growth of Proteobacteria (such as Pseudomonas aeruginosa and Escherichia coli) and certain bacteria of the Firmicutes phylum (Staphylococcus aureus and Enterococcus spp.). ${ }^{[57-59]}$ There is a loss of microbial diversity together with a wide range of existing gut microbes being replaced by more virulent microbes, which have a predilection for specific areas of the gut. This dysbiosis, which is the disruption in the normal dynamics of the microbiome, results in harmful host outcomes. ${ }^{\left[{ }^{[0]}\right.}$ As such strategies to map the gut microbiome with the view of manipulating the microorganism landscape has become an area of intensive research and interest. Interventions such as faecal transplantation are being explored as a strategy to restore gut health and function.

\section{Decatecholaminisation}

Sepsis is characterised by autonomic dysfunction attributed to excessive adrenergic stimulation. ${ }^{[61]}$ While this response may be beneficial in the early stages of the disease, the sustained adrenergic stress drives cytokine production and myocardial depression, and induces a state of catabolism contributing to the propagation of organ dysfunction. ${ }^{[62]}$ Hence, the concept of decatecholaminisation is proposed as a means to reduce the amount of circulating noradrenaline and adrenaline by attenuating the sympathetic drive with the expectation of improving haemodynamics, cellular metabolism and modulation of the immune system by limiting cytokine production. ${ }^{[63]}$ Consequently, esmolol (cardio-selective beta-1 adrenergic blocker) and dexmedetomidine (alpha-2 adrenoreceptor agonist) are being investigated for their anti-adrenegic properties. ${ }^{[64-66]}$ Dexmedetomidine also appears to be attractive owing to its anti-inflammatory properties and its organ protective effects. ${ }^{[67]}$

Beta-blocker therapy has sympatholytic properties and is associated with a reduction in the patient's heart rate without significantly dropping the mean arterial pressure. This therapy improves diastolic filling, which increases stroke volume and enhances coronary perfusion. ${ }^{[64,65,68,69]}$ Betablockers have also been shown to reduce catabolism by reducing energy expenditure, gluconeogenesis, hyperglycaemia and proteolysis' thus dampening the hypermetabolic response. ${ }^{[70]}$ It has been suggested that cell apoptosis and the release of pro-inflammatory mediators may be induced by beta-1 stimulation whereas down-regulation of the innate immune system and prolongation of cell life may be associated with Beta-2 stimulation. ${ }^{[71,72]}$ Beta-blockers may thus be of use to modulate the immune system by possibly up-regulating pro-inflammatory cytokines and down-regulating anti-inflammatory cytokines as well as reducing platelet aggregation and adhesion, thereby attenuating sepsis-induced coagulopathy. ${ }^{[73-75]}$ Beta-blocker therapy has been shown to reduce the incidence of arrhythmias, improve myocardial functioning and maybe reduce endotheliopathy by attenuating the catecholamine surge. The few available clinical studies have initiated beta-blocker therapy well after
24 hours from ICU admission. The optimal timing for initiation of this therapy as well as its duration still remains unclear and thereforeh no recommendations can be made at this stage.

\section{Heparin}

Heparin administration has been advocated in view of its immunomodulating and antithrombotic effects. While a retrospective study demonstrated a mortality benefit in septic shock, the more recent randomised placebo controlled HETRASE trial which explored the administration of $500 \mathrm{U}$ of heparin/hour in a cohort of 319 patients did not find any outcome benefit with such a strategy. ${ }^{[7,77]}$ Currently, ongoing trials are evaluating the role of differing dosing regimens of heparin in this population. Additionally, the utility of antithrombin and thrombomodulin is also being investigated.

\section{Miscellaneous}

Levosimendan, a calcium-sensitising inotrope, is thought to have anti-inflammatory properties which has been postulated to attenuate sepsis-associated cardiac dysfunction; however, the recent LeoPARDS trial does not support its use in sepsis. ${ }^{[8,79]}$ Therapies that have failed to show any benefit include statins, naloxone, pentoxyfylline, nitric oxide inhibitors and toll-like receptor antagonists.

\section{Conclusion}

The devastating impact of sepsis on individual patients and society at large has fuelled extensive research around this ill-understood disease. In terms of the new adjunctive therapies that are coming to the fore, the concepts of metabolic resuscitation, decatecholaminisation with betablockers and attenuating the pro-inflammatory cytokine storm with haemoadsorption are particularly attractive.

Acknowledgements. None.

Author contributions. JMC: 40\%; LM: $20 \%$; FP: $40 \%$.

Funding. None.

Conflicts of interest. FP has served on the speaker bureaux for Litha, Abbvie and Dr Reddy's and has also received an unrestricted research grant (Abbvie) as well as congress travel grants (Abbvie).

1. Angus DC, Linde-Zwirble WT, Lidicker J, et al. Epidemiology of severe sepsis in the United States: Anus DC, Linde-Zwirble WI, Lidicker J, et al. Epidemiology of severe sepsis in the United States; Analysis of incidence, outcome, and associated costs of
https://doi.org/10.1097/00003246-200107000-00002

2. Angus DC, van der Poll T. Severe sepsis and septic shock. New Engl J Med 2013;369(9):840-851. https://doi.org/10.1056/nejmra1208623

3. Wang HE, Shapiro NL, Angus DC, et al. National estimates of severe sepsis in United States emergency departments. Crit Care Med 2007:35(8):1928-1936. https://doi.org/10.1097/01. ccm.0000277043.85378.cl

4. Rhodes A, Evans LE, Alhazzani W, et al. Surviving Sepsis Campaign: International guidelines for management of sepsis and septic shock: 2016. Intensive Care Med 2017;43(3):304-377. https://doi. org/10.1097/ccm.0000000000002255

5. Singer M, Deutschman CS, Seymour CW, et al. The Third International Consensus Definitions for Sepsis and Septic Shock (Sepsis-3). JAMA 2016;315(8):801-810. https://doi.org/10.1001/ jama.2016.0287

6. Takeuchi O, Akira. S. Pattern recognition receptors and inflammation. Cell 2010;140(6):805-820 https://doi.org/10.1016/j.cell.2010.01.022

7. Polat G, Ugan RA, Cardirci E, Halici Z. Sepsis and septic shock: Current treatment strategies and new approaches. Eurasian J Med 2017;49(1):53-58. https://doi.org/10.5152/eurasianjmed.2017.17062

8. Russell JA. Management of sepsis. N Engl J Med 2006;355:1699-1713. https://doi.org/10.1056/ nejmra043632

9. Hattori Y, Hattori K, Suzuki T, Matsuda N. Recent advances in the pathophysiology and molecular basis of sepsis-associated organ dysfunction: Novel therapeutic implications and challenges. Pharmacol Ther 2017;177: 56-66. https://doi.org/10.1016/j.pharmthera.2017.02.040

10. Rivers E, Nguyen S, Havstad, et al. Early goal directed therapy in the treatment of severe sepsis and septic shock. New Engl J Med 2001;345:1368-1377. https://doi.org/10.1056/nejmoa010307

11. Carré J, Singer M, Moncada S. Nitric Oxide. In: Abraham E, Singer M (eds). Mechanisms of SepsisInduced Organ Dysfunction and Recovery. Update in Intensive Care and Emergency Medicine 2007 vol 44. Springer, Berlin, Heidelberg. https://doi.org/10.1007/3-540-30328-6_6

12. Cohen J, Vincent JL, Adhikari NK, et al. Sepsis: A roadmap for future research. Lancet Infect Dis 2015;15(5):581-614. https://doi.org/10.1016/s1473-3099(15)70112-x

13. Czura CJ. Merinoff Symposium 2010: Sepsis - speaking with one voice. Mol Med 2011;17:2-3. https://doi.org/10.2119/molmed.2010.00001.commentary 
14. Brown KA, Brain SD, Pearson JD, et al. Neutrophils in development of multiple organ failure in sepsis. Lancet 2006;368:157-169. https://doi.org/10.1016/s0140-6736(06)69005-3

15. Galley HF, Webster NR. The immuno-inflammatory cascade. Br J Anaesth. 1996;77:11-16. https:// doi.org/10.1093/bja/77.1.11

16. Delano MJ, Thayer T, Gabrilovich S, et al. Sepsis induces early alterations in innate immunity that impact mortality to secondary infection. J Immunol 2011;186(1):195-202. https://doi.org/10.4049/ jimmunol.1002104

17. Boomer JS, Shuherk -Shaffer J, Hotchkiss RS, Green JM. A prospective analysis of lymphocyte phenotype and function over the course of acute sepsis. Crit Care 2012;16:112. https://doi. org/10.1186/cc11404

18. McConnell KW, Coopersmith CM. Pathophysiology of septic shock: From bench to bedside. Presse Med 2016;45:e93-e98. https://doi.org/10.1016/j.lpm.2016.03.003

19. Shao R, Fang Y, Yu H, et al. Monocyte programmed death ligand-1 expression after 3 - 4 days of sepsis is associated with risk stratification and mortality in septic patients: A prospective cohort study. Crit Care 2016;20(1):124. https://doi.org/10.1186/s13054-016-1301-x

20. Monneret G, Gossez M, Venet F. Sepsis in PD-1 light. Crit Care 2016;20:186. https://doi. org/10.1186/s13054-016-1370-x

21. Fabbri LP, Santarlasci V, Nucera M, et al. Correlation between markers of Th2-oriented response and SOFA score in sepsis. Open Crit Care Med J 2008;1:17-23. https://doi. org $/ 10.2174 / 1874828700801010017$

22. Levi M, van der Poll T. Coagulation in patients with severe sepsis. Semin Thromb Hemost 2015;41(01):009-015. https://doi.org/10.1055/s-0034-1398376

23. Babrowski T, Romanowski $K$, Fink $\mathrm{D}$, et al. The intestinal environment of surgical injury transforms Pseudomonas aeruginosa into a discrete hypervirulent morphotype capable of causing lethal peritonitis. Surgery 2013;153(1):36-43. https://doi.org/10.1016/j.surg.2012.06.022

24. Opal SM, Laterre PF, Francois B, et al. Effect of eritoran, an antagonist of MD2-TLR4, on mortality in patients with severe sepsis: The ACCESS randomized trial. JAMA 2013;309(11):1154-1162. https://doi.org/10.1001/jama.2013.2194

25. Rice TW, Wheeler AP, Bernard GR, et al. A randomized, double-blind, placebo-controlled trial of TAK-242 for the treatment of severe sepsis. Crit Care Med 2010;38(8):1685-1694. https://doi. org/10.1097/ccm.0b013e3181e7c5c9

26. Martin TR. MIF mediation of sepsis. Nat Med 2000;6(2):140-141. https://doi.org/10.1038/72230

27. Fisher CJ Jr, Dhainaut JF, Opal SM, et al. Recombinant human interleukin 1 receptor antagonist in the treatment of patients with sepsis syndrome. Results from a randomized, double-blind, placebocontrolled trial. JAMA 1994;271(23):1836-1843. https://doi.org/10.1001/jama.271.23.1836

28. Peng ZY, Carter MJ, Kellum JA. Effects of hemoadsorption on cytokine removal and shortterm survival in septic rats. Crit Care Med 2008;36:1573-1577. https://doi.org/10.1097/ ccm.0b013e318170b9a7

29. Honore PM, Jacobs R, Joannes-Boyau O, et al. Newly designed CRRT membranes for sepsis and SIRS - a pragmatic approach for bedside intensivists summarizing the more recent advances: A systematic - a pragmatic approach for bedside intensivists summarizing the more recent advances: A sys
structured review. ASAIO J 2013;59:99-106. https://doi.org/10.1097/mat.0b013e3182816a75

30. Schadler D, Brederlau J, Jorres A, et al. Extracorporeal cytokine hemoadsorption in patients with severe sepsis and acute lung injury. Am J Respir Crit Care Med 2013, 187:A5241. https://doi. org/10.1371/journal.pone.0187015

31. Reeves JH. A review of plasma exchange in sepsis. Blood Purif 2002;20(3):282-288. https://doi. org/10.1159/000047021

32. Livigni S, Bertolini G, Rossi C, et al. Efficacy of coupled plasma filtration adsorption (CPFA) in patients with septic shock: A multicenter randomised controlled clinical trial. BMJ Open 2014;4:e003536. https://doi.org/10.1136/bmjopen-2013-003536

33. Joannes-Boyau O, Honoré PM, Perez P, et al. High-volume versus standard-volume haemofiltration for septic shock patients with acute kidney injury (IVOIRE study): A multicentre randomized controlled trial. Intensive Care Med 2013;39(9):1535-1546. https://doi.org/10.1007/s00134-013$2967-z$

34. Borthwick EM, Hill CJ, Rabindranath KS, et al. High-volume haemofiltration for sepsis. Cochrane Database Syst Rev 2013;(1):CD008075. https://doi.org/10.1002/14651858.cd008075.pub2

35. Cruz DN, Antonelli M, Fumagalli R, et al. Early use of polymyxin B hemoperfusion in abdominal septic shock: The EUPHAS randomized controlled trial. JAMA 2009;301:2445-2452. https://doi. org/10.1001/jama.2009.856

36. Fujii T, Ganeko R, Kataoka Y, et al. Polymyxin B-immobilized hemoperfusion and mortality in critically ill adult patients with sepsis/septic shock: A systematic review with meta-analysis and trial sequential analysis. Intensive Care Med 2018;44:167-178. https://doi.org/10.1007/s00134-0175004-9

37. Kogelman K, Jarczak D, Scheller M, Druner M. Hemoadsorption by Cytosorb in septic patients: A case series. Crit Care 2017;21:74. https://doi.org/10.1186/s13054-017-1662-9

38. Basu R, Pathak J, Chaudhry R, et al. Use of a novel hemoadsorption device for cytokine removal as adjuvant therapy in a patient with septic shock with multi-organ dysfunction: A case study. Ind J Crit Care Med 20114;18(12):822-824. https://doi.org/10.4103/0972-5229.146321

39. Friesecke S, Stecher SS, Gross S, et al. Extracorporeal cytokine elimination as rescue therapy in refractory septic shock: A prospective single-center study. J Artf Organs 2017;20(3):252-259. https:// doi.org/10.1007/s10047-017-0967-4

40. Friesecke S, Trager K, Schittek GA, et al. International registry on use of the Cytosorb adsorber in ICU patients: Study protocol and preliminary results. Med Klin Intensivmed Notfmed (2017] https://doi.org/10.1007/s00063-017-0342-5

41. Venkatesh B, Finfer S, Cohen J, et al. Adjunctive glucocorticoid therapy in patients with septic shock. N Engl J Med 2018;378(9):797-808. https://doi.org/10.1056/nejmoal705835

42. Annane D, Renault A, Brun-Buisson C, et al. Hydrocortisone plus fludrocortisone for adults with septic shock. N Engl J Med 2018;378(9):809-818. https://doi.org/10.1056/nejmoal705716

43. Annane D, Bellissant E, Bollaert PE, et al. Corticosteroids for treating sepsis. Cochrane Database Syst Rev 2015;(12):CD002243. https://doi.org/10.1002/14651858.cd002243.pub3

44. Alejandria MM, Lansang MA, Dans LF, Mantaring JB. Intravenous immunoglobulin for treating sepsis, severe sepsis and septic shock. Cochrane Database Syst Rev 2013;(9):CD001090. https://doi. org/10.1002/14651858.cd001090.pub2

45. Werdan K, Pilz G, Bujdoso O, et al. Score-based immunoglobulin G therapy of patients with sepsis: The SBITS study. Crit Care Med 2007;35:2693-2701. https://doi.org/10.1097/00003246-20071200000003

46. Leite HP, de Lima LFP. Metabolic resuscitation in sepsis: A necessary step beyond the hemodynamic? J Thorac Dis 2016;8(7): E552-E557. https://doi.org/10.21037/jtd.2016.05.37
47. Donnino MW, Andersen LW, Chase M, et al. Randomized, double-blind, placebo-controlled trials of hiamine as a metabolic resuscitator in septic shock: A plot study. Crit Care Med 2016;44(2):360-367. https://doi.org/10.1097/ccm.0000000000001572

48. Andersen LW, Mackenhauer J, Roberts JC, et al. Etiology and therapeutic approach to elevated lactate. Mayo Clin Proc 2013;88(10): 1127-1140. https://doi.org/10.1016/..mayocp.2013.06.012

49. Berger M, Oudemans-van Straaten HM. Vitamin C supplementation in the critically ill patient. Curr Opinion Clin Nutri Metab Care 2015;18(2):193-201. https://doi.org/10.1097/

50. Yao X, Carlson D, Sun Y, et al. Mitochondrial ROS induces cardiac inflammation via a pathway through mtDNA damage in a pneumonia-related sepsis model. PLoS ONE 2015;10(10):e0139416. https://doi.org/10.1371/journal.pone.0139416

51. Rayman MP. Selenium and human health. Lancet 2012;379(9822):1256-1268. https://doi. org/10.1016/s0140-6736(11)61452-9

52. Terrin G, Berni Canani R, Passariello A, et al. Zinc supplementation reduces morbidity and mortality in very-low-birth-weight preterm neonates: A hospital based randomized, placebocontrolled trial in an industrialized country. Am J Clin Nutr 2013;98(6):1468-1474. https://doi. org/10.3945/ajcn.112.054478

53. Marik PE, Khangoora V, Rivera R, et al. Hydrocortisone, vitamin C, and thiamine for the treatment of severe sepsis and sepic shock: A retrospective before-after study. Chest 2017;151(6):1229-1238. https://doi.org/10.1016/j.chest.2016.11.036

54. Galley HF, Lowes DA, Allen L, et al. Melatonin as a potential therapy for sepsis: A phase I dose escalation study and an ex vivo whole blood model under conditions of sepsis. I Pineal Res 2014;56(4):427-438. https://doi.org/10.1111/jpi.12134

55. Demehri FR, Barrett M, Ralls MW, et al. Intestinal epithelial cell apoptosis and loss of barrier function in the setting of altered microbiota with enteral nutrient deprivation. Front Cell Infect Microbiol 2013;3:105. https://doi.org/10.3389/fcimb.2013.00105

56. Hand TW. The role of the microbiota in shaping infectious immunity. Trends Immunol 2016;37(10):647-658. https://doi.org/10.1016/j.it.2016.08.007 57. Rynda-Apple A, Robinson KM, Alcorn JF. Influenza and bacterial superinfection: Illuminating
the immunologic mechanisms of disease. Infect Immun 2015;83(10):3764-3770. https://doi. org/10.1128/iai.00298-15

58. Modi SR, Collins JJ, Relman DA. Antibiotics and the gut microbiota. J Clin Invest 2014;124(10):4212 4218. https://doi.org/10.1172/jci72333

59. Prescott HC, Dickson RP, Rogers MA, et al. Hospitalisation type and subsequent severe sepsis. Am Respir Crit Care Med 2015;192(5):581-588. https://doi.org/10.1164/rccm.201503-0483oc

60. Kitsios GD, Morowitz MJ, Dickson RP, et al. Dysbiosis in the intensive care unit: Microbiome scienc coming to the bedside. J Crit Care.2017;38:84-91. https://doi.org/10.1016/j.jcrc.2016.09.029

61. Annane D, Trabold F, Sharshar T, et al. Inappropriate sympathetic activation at onset of septic shock: A spectral analysis approach. Am I Respir Crit Care Med 1999;160(2):458-465. https://doi.org/10.1164/ajrccm.160.2.9810073

62. Andreis DT, Singer M. Catecholamines for inflammatory shock: A Jekyll-and-Hyde conundrum. Intensive Care Med 2016;42(9):1387-1397. https://doi.org/10.1007/s00134-016-4249-z

63. Rudiger A, Singer M. Decatecholaminisation during sepsis. Crit Care 2016;20:309. https://do org/10.1186/s13054-016-1488-x

64. Morelli A, Ertmer C, Westphal M, et al. Effect of heart rate control with esmolol on hemodynamic and clinical outcomes in patients with septic shock: A randomized clinical trial. JAMA 2013;310(16):1683-1691. https://doi.org/10.1001/jama.2013.278477

65. Morelli A, Donati A, Ertmer C, et al. Microvascular effects of heart rate control with esmolol in patients with septic shock: A pilot study. Crit Care Med 2013;41(9):2162-2168. https://doi. org/10.1097/ccm.0b013e31828a678d

66. Reade MC, Eastwood GM, Bellomo R, et al. Effect of dexmedetomidine added to standard care on ventilator-free time in patients with agitated delirium: A randomized clinical trial. JAMA 2016;315(14):1460-1468. https://doi.org/10.1001/jama.2016.2707

67. Hofer S, Steppan J, Wagner T, et al. Central sympatholytics prolong survival in experimental sepsis. Crit Care 2009;13(1):R11. https://doi.org/10.1186/cc7709

68. Misonoo Y, Yajima S, Morisaki H, et al. Efficacy and safety of betal adrenoreceptor blockade by landiolol in sepsis. Crit Care Med 2009;37(12 Suppl):A239.

69. Gore DC, Wolfe RR. Hemodynamic and metabolic effects of selective betal adrenergic blockade during sepsis. Surgery 2006;139(5):686-694. https://doi.org/10.1016/j.surg.2005.10.010

70. Novotny NM, Lahm T, Markel TA, et al. Beta-blockers in sepsis: Reexamining the evidence. Shock 2009;31(2):113-119. https://doi.org/10.1097/shk.0b013e318180ffb6

71. Grisanti LA, Evanson J, Marchus E, et al. Pro-inflammatory responses in human monocytes are betal-adrenergic receptor subtype dependent. Mol Immunol 2010;47(6):1244-1254. https://doi. org/10.1016/.molimm.2009.12.013

72. Scanzano A, Cosentino M. Adrenergic regulation of innate immunity: A review. Front Pharmacol 2015;6:171. https://doi.org/10.3389/fphar.2015.00171

73. De Montmollin E, Aboab J, Mansart A, Annane D. Bench-to-bedside review: Beta-adrenergic modulation in sepsis. Crit Care 2009;13(5):230. https://doi.org/10.1186/cc8026

74. Muthu K, Deng J, Romano F, et al. Thermal injury and sepsis modulates beta-adrenergic receptor and cAMP responses in monocyte-committed bone marrow cells. J Neuroimmunol 2005;165(12):129-138. https://doi.org/10.1016/j.jneuroim.2005.04.015

75. Markel A, Brook JG, Levy Y, et al. Increased platelet adhesion and aggregation in hypertensive patients: Effect of atenolol. Br J Clin Pharmacol. 1983;16(6):663-668. https://doi. hypertensive patients: Effect of atenold.
org/10.1111/j.1365-2125.1983.tb02238.x

76. Zarychanski R, Doucette S, Fergusson D, et al. Early intravenous unfractionated heparin and mortality in septic shock. Crit Care Med 2008;36(11):2973-2979. https://doi.org/10.1097/ $\mathrm{ccm} .0 \mathrm{~b} 013 \mathrm{e} 31818 \mathrm{~b} 8 \mathrm{c} 6 \mathrm{~b}$

77. Jaimes F, De La Rosa G, Morales C, et al. Unfractioned heparin for treatment of sepsis: A randomized clinical trial (the HETRASE Study). Crit Care Med 2009;37(4):1185-1196. https://doi.org/10.1097/ccm.0b013e31819c06bc

78. Zangrillo A, Putzu A, Monaco F, et al. Levosimendan reduces mortality in patients with severe sepsis and septic shock: A meta-analysis of randomized trials. J Crit Care 2015;30(5):908-913. https://doi. org/10.1016/j.jcrc.2015.05.017

79. Gordan AC, Perkins GD, Singer M, et al. Levosimendan for the prevention of acute organ dysfunction in sepsis. N Engl J Med 2016;375(17):1638-48. https://doi.org/10.1056/nejmoa1609409 